\title{
Study on Incremental Launching of Lane L8 Steel Box Girder of Main Bridge in Xiamen Xianyue Flyover
}

\author{
Zhengwei Feng ${ }^{1,}$, , Renbo Que ${ }^{1}$ \\ ${ }^{1}$ Department of Civil Engineering, Xiamen University Tan Kah Kee College, \\ Zhangzhou, Fujian Province, China, 363105 \\ aemail: fengzhengwei@xujc.com
}

\begin{abstract}
Keywords: Steel Box Girder; Multiple Segments; Incremental Launching; Scheme Comparison and Selection; Curve shape

Abstract. The Lane L8 of main-bridge of Xianyue Flyover across over Success Avenue is a reconstruction project with span of $39 m+50 m+39 m$. The circular-curved steel box girder has a uniform cross section with a multi-chamber single box. The characteristics of drag-type incremental launching and segment division of steel box girder were first introduced. In view of the characteristics such as curve shape, multiple segments and road complexity, and by comprehensively analyzing site condition, transportation condition and anti-overturning stability, the multipoint unidirectional twice-launching method was adopted herein, and its construction process was introduced. The technical problem such as disengagement of the steel girder from incremental launching platform in the course of launching was solved by jacking and real-time monitoring. The construction schedule was sped up, and meanwhile, safety was guaranteed. This study can provide valuable references for similar engineering projects.
\end{abstract}

\section{Introduction}

Xianyue Road is located in the middle of Xiamen Island, extending from Haicang Bridge in the west to Xiang'an Tunnel in the east. It is an important way of $12 \mathrm{~km}$ linking Haicang District with Xiang'an District. Together with Success Avenue that is N-S trending, it constitutes the skeleton of the expressway network of Xiamen city [1]. The reconstruction project aims to cover the west area of Jinshang Road with viaduct along Xianyue Road, and to form an all-interworking stereoscopic traffic system of three layers at the intersection of Xianyue Road and Success Avenue so as to ease traffic and reduce jam.

The Lane L8 of main bridge crosses over the ramp from the main road of Success Avenue to Xianyue Road. The bottom of girder elevates $13.1 \mathrm{~m}$ to $18.3 \mathrm{~m}$ from Xianyue Road, $9 \mathrm{~m}$ or so from Success Avenue, and $5.7 \mathrm{~m}$ from the ramp. The Lane L8 has 3 spans with span of $39 \mathrm{~m}+50 \mathrm{~m}+39 \mathrm{~m}$. Its plane layout is in form of straight line, and vertical section is in form of circular-curve with curvature radius of $3497.854 \mathrm{~m}$. It is constructed by the steel box girder with uniform and circular-curve cross section with a multi-chamber single box, which is $2 \mathrm{~m}$ high, $25 \mathrm{~m}$ wide on the top, and $13.5 \mathrm{~m}$ wide at the bottom. The cantilever on each side is $5.75 \mathrm{~m}$ long. Q345C steel boards are used for overall bridge with cross section shown in Fig.1 [2].

The whole bridge consists of 22 segments, which weigh $1420 t$ in all. The largest girder segment weighs $83.9 \mathrm{t}$. It is $25 \mathrm{~m}$ long, $6.295 \mathrm{~m}$ wide and $2 \mathrm{~m}$ high. The drag-type multipoint unidirectional continuous incremental launching method is adopted herein so as to reduce adverse effects on traffic of Success Avenue. The girder segment is dragged via steel cables attached with jack to slide along the incremental launching platform on the pier tops, and mounted in place step by step.

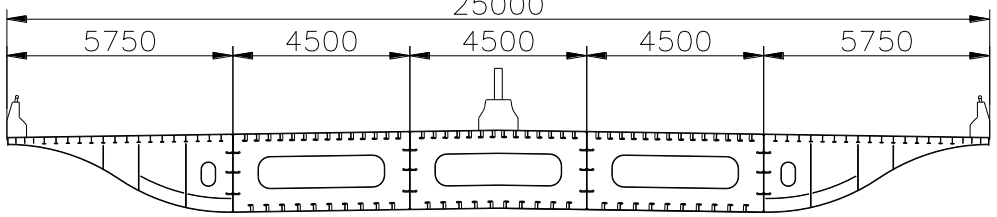

Fig.1 Cross Section of Steel Box Girder 


\section{Incremental Launching Schemes for Steel Box Girder}

\subsection{Drag-type Multipoint Incremental Launching}

2.1.1 Principle of Drag-type Incremental Launching. Currently, the popular incremental launching technology for bridges in China is a drag-type multipoint incremental launching. It is such a construction method that is to drag assembled steel box girder segment to slide along the incremental launching rail on temporary pier tops via steel cables attached with jack, and then install them in place [3].

Incremental launching needs such tools as a slide system (including tetrafluoro slide board, steel bearing beams etc.), a dragging system (including hydraulic jack, reaction frame, dragging cable, tensile anchor etc.), and a vertical adjustment system (including vertical jack, and steel cushion), and so on [4].

The launching nose is used herein so as to prevent the potential risk induced by overstressing of internal members of the girder when the girder is in the cantilever state during dragging.

2.1.2 Characteristics of Drag-type Incremental Launching via Launching Nose. (1) The horizontal load on the pier is the resultant force of the reaction bearing force and the friction force during the translation of steel box girder. Theoretically speaking, it's small. However, due to uneven force on different fulcrums, there is still a certain amount of horizontal force.

(2) In the course of translation of steel box girder, the vertical load on each pier keeps changing, and thus the friction force will vary accordingly. Dragging force needs to be adjusted continuously in line with the friction force so as to avoid too much horizontal load. It has to strictly guarantee independence of pressure regulating of the pump station [5].

(3) Wedges or jacks can be used to correct deviation in the course of central line adjustment.

(4) The technology is much developed and construction progress is fast.

2.2 Division of Segments of Steel Box Girder. In line with the characteristics of the span, the uniform section and curve shape, and a multi-chamber single box, and considering fully fabrication difficulty, transportation overload and limitations on weight and dimensions of segments during hoisting, and guaranteeing the structural stability of each box girder segment during transporting and hoisting, we divide the steel box girder into 22 segments longitudinally, but not transversely.

The Lane L8 has 3 spans with span of $39 m+50 m+39 m$, which are located on 21 st to 24 th main piers. It is sequentially hoisted from segments marked with letters from A to U. Each segment is $25 \mathrm{~m}$ long, $2 \mathrm{~m}$ high and $6 \mathrm{~m}$ or so wide. The segment $\mathrm{G}$ is the largest one of $83.9 \mathrm{t}$. The steel box girder is segmented and assembled on one side, and is incrementally launched from east to west in multipoint unidirectional way. The overall structure arrangement is shown in Fig.2.

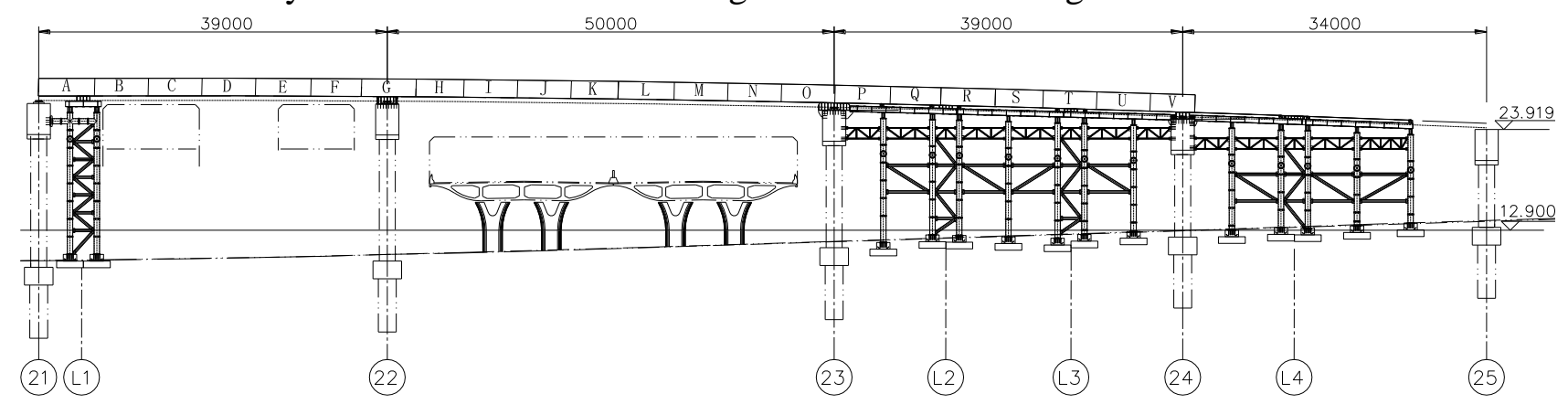

Fig.2 The Overall Structure Arrangement

2.3 Comparison and Selection of Incremental Launching Schemes. The second span (50m long) of steel box girder of Lane L8 crosses over Success Avenue. During construction, Success Avenue should be not closed as far as possible. The continuous girder will repeatedly pass the main piers and temporary piers. When the span is longer than $50 \mathrm{~m}$, the bending moment of the steel box girder will drastically increase, and thus construction difficulty will significantly increase. Whether to build the temporary piers between the 22nd and 23rd piers has become the key of scheme comparison and selection. 
If incremental launching platform is too short, it requires multiple times of incremental launching and assembly, which will result in suspension of steel box girder over Success Avenue for too long. If incremental launching platform is too long, it is difficult to provide enough places for assembly. The span arrangement and construction scheme of the project should be decided according to onsite condition and traffic condition. There are two optional schemes.

For Scheme I, in order to reduce the suspension time of the launching nose and part of steel box girder segment with span of $50 \mathrm{~m}$, incremental launching should be completed at one step. There are 11 segments in total (A to K). The shortest incremental launching platform is $89.5 \mathrm{~m}$ long.

For Scheme II, in light of the onsite condition, incremental launching will be completed twice. First, push the launching nose out of the incremental launching platform by 25m, as shown in Fig.3. And then incrementally launch the subsequent segments to the 22nd pier along the launching nose, as shown in Fig.4. The launching nose is $30 \mathrm{~m}$ long and $55 \mathrm{t}$ in weight. The shortest incremental launching platform is $73 \mathrm{~m}$ long. The scheme comparison is shown in Table 1, and after comprehensively analyzing and comparing two schemes, we chose scheme II.

\section{Table 1 Comprehensive Comparison of Two Schemes}

\begin{tabular}{|l|l|l|l|}
\hline NO. & Anti-overturning Stability Coefficient & Advantages and Disadvantages \\
\hline I & $1.16<1.3$ & $\begin{array}{l}\text { Advantages: one-step incremental launching can } \\
\text { avoid long suspension time of the launching nose. } \\
\text { Disadvantages: the requirement of anti-overturning } \\
\text { stability is difficult to meet when the incremental } \\
\text { launching platform is too long because of limitation } \\
\text { of onsite conditions. }\end{array}$ \\
\hline \multirow{3}{*}{ II } & $\begin{array}{l}\text { Step 1: The launching nose is } \\
\text { launched out of the } \\
\text { incremental } \\
\text { platform by 25m. launching }\end{array}$ & $1.42>1.3$ & $\begin{array}{l}\text { Advantages: Both the requirement of } \\
\text { anti-overturning stability and the onsite } \\
\text { construction condition can be met. } \\
\text { Disadvantages: Two-step incremental launching } \\
\text { will result in suspension of the launching nose for } \\
\text { long time }\end{array}$ \\
\cline { 2 - 5 } & $\begin{array}{l}\text { Step 2: The launching noise } \\
\text { is close to the 22nd pier. }\end{array}$ & $1.6>1.3$ \\
\hline
\end{tabular}

In view of adverse effect of incremental launching on the traffic of Success Avenue, no temporary pier is built between two adjacent main piers $50 \mathrm{~m}$ apart. For the scheme I, the incremental launching platform is $89.5 \mathrm{~m}$ long, and there is no enough space for assembly. What's more, the requirement of anti-overturning stability can't be met. Therefore, the scheme II is selected herein. The span is of $50 \mathrm{~m}$ over Success Avenue, and the incremental launching is completed in two steps. The cantilever of the launching nose is $25 \mathrm{~m}$ long for the first time, and the launching nose is incrementally launched to cross over the pier for the second time. The requirement of anti-overturning stability can be met when the launching nose is in the cantilever, and the span between $23 \mathrm{rd}$ to 25 th piers is equal to the length of the incremental launching platform (i.e. $39 m+34 m=73 m$ ). Some space of the first span of Lane L9 is occupied.

In actual construction, it took 7 days to launch the first part of $25 \mathrm{~m}$, and then nearly 3 hours to launch the rest to cross over the pier. The first span of Lane L9 has been occupied for around 25 days. Both the suspension time of cantilever segments and the time of incremental launching crossing over Success Avenue are greatly reduced. It proves that the scheme is feasible.

\section{Incremental Launching technology of Steel Box Girder}

In the course of incremental launching, due to onsite limitations, the platform between 24th and 25th main piers of the first span of Lane L9 is occupied. The incremental launching platform is located between the 21 st to 25 th main piers, consisting of 5 main piers (21st to 25th), and 4 temporary piers (L1, L2, L3, and L4), as shown in Fig.2.

The main steps are as follows. 
(1) Erect the assembly platform and treat its foundation. Install the slide rail, inhibiting device, and the dragging power device.

(2) Assemble the box girder and the launching nose.

Assemble the launching nose of 30m and 7 segments (i.e. A, B, C, D, E, F and G) on the erected assembly platform. Set a back anchorage point at the tail of the G segment, embed the bracket in the top part of the 23rd pier, and install the dragging equipment and complete adjustment.

(3) Transform of load carrying.

By sliding the cylinder on the slide fulcrum, the assembled box girder is laid down onto the slide fulcrum from the temporary cushion block that is used during assembly.

(4) Dragging and sliding

The box girder is dragged with the steel cables between the lugs on the steel box girder and the reaction frames. Drag the first unit to move out by $25 \mathrm{~m}$, in such a way the steel launching nose can be incrementally launched out of the platform by $25 \mathrm{~m}$ and in a cantilever state, as shown in Fig. 3

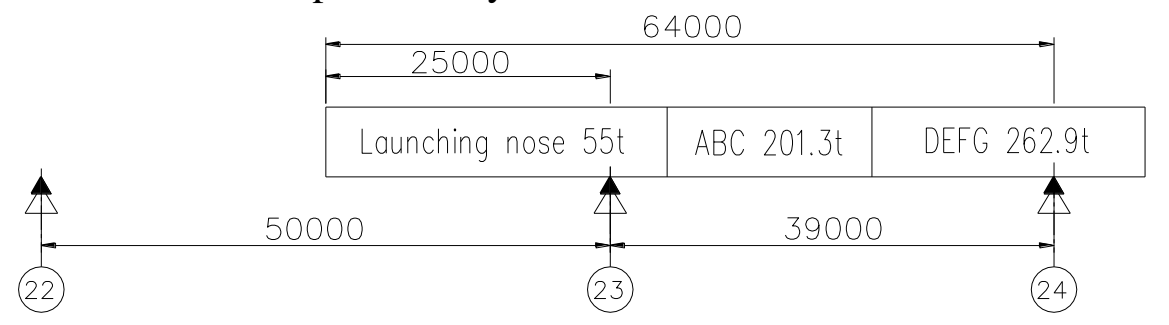

Fig.3 Incremental Launching for the First Time

(5) Assemble subsequent box girder segments

Lift the subsequent segments (i.e., H, I, J and K) to the assembly platform and finish assembly. Then lay them down to the sliding rail and keep dragging to the 22nd pier along the launching nose, as shown in Fig.4. And then move the launching nose on the 22nd pier forward by $25 \mathrm{~m}$.

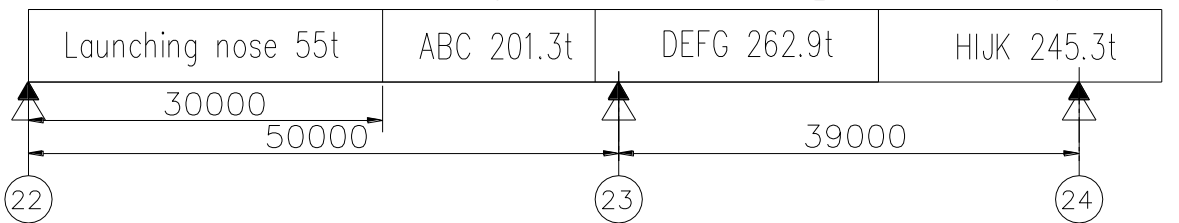

Fig.4 Incremental Launching of Launching Nose to the 22nd Pier

(6) Adjust the form of central line, assemble the subsequent segments (i.e., L, M, N, and O), and move the launching nose to the 21 st pier. Then keep dragging. Dismantle a launching nose segment of $5 \mathrm{~m}$ by removing the connecting bolt between segments of the launching noses whenever drag of $5 \mathrm{~m}$ is finished until the segment A reaches the 21 st pier. And then assemble the subsequent segments (i.e., $\mathrm{P}, \mathrm{Q}, \mathrm{R}, \mathrm{S}, \mathrm{T}, \mathrm{U}$ and $\mathrm{V}$ ).

(7) Lower the girder: After the girder is launched in place and adjusted well, lift structure via the cylinder on the slide fulcrum and then dismantle the slide fulcrum, lower the girder to the permanent pier and finish the construction.

\section{Technological Challenges and Solutions}

4.1 Horizontal Force Control of Incremental Launching Pier. Considering the vertical circular curve shape, we employed the multipoint incremental launching so as to reduce horizontal counter-force of the piers, and used 21st, 23rd and 24th main piers as the incremental launching piers. At the stage before incremental launching, the 21st main pier doesn't function. The incremental launching equipment on the 23rd and 24th main piers takes effect horizontally. Friction force varies accordingly with vertical force on each pier. So each slide rail undergoes different horizontal force. The incremental launching force can be adjusted automatically via the main control station in line with the friction force and displayed on the oil pressure indicator, and it needs to calculate and monitor the horizontal force so as to prevent the 23rd and 24th main piers from undergoing excessive horizontal counter-force. 
Incremental launching acceleration can be adjusted via the incremental launching equipment controlled by computer so as to stabilize the incremental launching and reduce inertial load. Exposed to the temperature, long steel box girder will expand or contract greatly and result in horizontal load, which can be eliminated by the slide structure [6].

4.2 Curve Form Control of Steel Box Girder during Incremental Launching. The 21st to 24th axes of Lane L8 have 3 spans with span of 39m, 50m and 39m, respectively. As for as the bridge alignment, the plane is in the shape of straight line, and the vertical section is in the shape of circular curve with curvature radius of $3497.8 \mathrm{~m}$. The steel box girder may disengage from the slide rail during incremental launching because of the vertical curve.

In order to solve such a problem, we chose the multipoint unidirectional incremental launching. The elevation of the incremental launching platform and the slide rail on piers is determined according to the circular curve, and incremental launching is conducted parallel to the circular curve of the girder bottom of completed bridge. Meanwhile, three-directional jacks are mounted on two sides of the slide rail, as shown in Fig.11. During assembly, the form of central line can be adjusted in light of measuring data. The vertical elevation can be adjusted at intervals according to the monitoring data so as to achieve the curve form desired.

\section{Conclusions}

The multi-segment twice-incremental launching scheme is adopted for the steel box girder of Lane L8 of main bridge of Xianyue Flyover in Xiamen. It is characterized by pushing the launching nose out of the incremental launching platform by $25 \mathrm{~m}$ for the first time and incrementally launching the launching nose to the 22nd pier after the subsequent segments are assembled. The difficulties encountered in the course of production, transportation and hoisting of segments can be solved well. Meanwhile, the onsite construction condition is given full consideration so as to shorten suspending and incremental-launching time of the segments, and thus the safety of structure is guaranteed and construction risk is reduced.

The horizontal force of the incremental launching piers and the line form can be controlled via the jacks and the real-time monitoring. To sum up, the incremental launching herein is safe, reliable, economical, and short in construction period. It can provide useful references for similar engineering projects.

\section{References}

[1] Liu Xinyi, etal. Scheme Comparison and Selection for Jacking-up of Continuous Steel Box Beam Bridge and Key Techniques Used [J]. World Bridges, 2016, 44(1):87-91. (In Chinese)

[2] Lin Dingmo. The application of deviation rectification technique with hydraulic control system in rectifying deviation due to traction sliding for steel box girder in bridge engineering[J]. Installation, 2016(03):46-49. (In Chinese)

[3] Tan Xinghua, etal. Study on incremental launching technique of trough girders of Jiupu Bridge [J]. Highway, 2010(06):92-97. (In Chinese)

[4] Song Yanxu. Study on structural performance of steel box girder bridge during the incremental launching construction stage [D]. Beijing:Beijing Jiaotong University, 2010. (In Chinese)

[5] Yan Haicheng. Hydraulic Walking, Multi-point Launching Construction Techniques for Steel Box Girders Across an Existing Railway [J].Traffic Engineering and Technology for National Defense. 2012(03):44-46. (In Chinese)

[6] Guan Yueyuan. Study on the Self-Anchored Suspension Bridge Superstructure of Pushing the Construction of Key Technologies [D]. Xi'an: Chang'an University, 2012. (In Chinese) 